\title{
Combining Bio-Cultural and Asset Based Approach Towards Sustainable Utilization of Catchment Resources
}

\author{
Agnes Kapinga ${ }^{1, *}$, Olanyika Ogunkoya ${ }^{2}$, Abimbola Sangodoyin ${ }^{3}$, Peter Meta $^{4}$, Bety Begashe $^{5}$ \\ ${ }^{1}$ Department of Environmental Management, Pan Africa University Life and Earth Sciences Institute (PAULESI), University of Ibadan, \\ Ibadan, Nigeria \\ ${ }^{2}$ Department of Geography, Obafemi Awolowo University, Ile- Ife, Nigeria \\ ${ }^{3}$ Department of Agriculture and Environmental Engineering, University of Ibadan, Ibadan, Nigeria \\ ${ }^{4}$ Department of Biology, Korogwe Teachers College, Tanga, Tanzania \\ ${ }^{5}$ Department of management sciences, University of Dodoma, Tanzania
}

Email address:

agnesgisbertkapinga@gmail.com (A. Kapinga), olayinkaogunkoya@gmail.com (O. Ogunkoya), bimbo_sangodoyin@yahoo.co.uk (A. Sangodoyin),mrechatz@gmail.com (P. Meta), b.begashe@gmail.com (B. Begashe)

${ }^{*}$ Corresponding author

\section{To cite this article:}

Agnes Kapinga, Olanyika Ogunkoya, Abimbola Sangodoyin, Peter Meta, Bety Begashe. Combining Bio-Cultural and Asset Based Approach Towards Sustainable Utilization of Catchment Resources. American Journal of BioScience. Vol. 6, No. 1, 2018, pp. 15-22. doi: 10.11648/j.ajbio.20180601.13

Received: February 2, 2018; Accepted: February 16, 2018; Published: March 16, 2018

\begin{abstract}
Water security is one of the key sustainability challenges in this modern era regardless of the level of development. While the problem keep on increasing year after year, man is a dominant player over hydrological system and also possesses powerful ways and means of utilizing hydrological resources and responds to hydrological dynamics in different ways. The utilization of hydrological resources is influenced by natural resources which are available in the aquatic system, communities' culture and assets. These three main factors can be divided into two groups, namely, bio-cultural and community/ anthropogenic asset. Bio-cultural asset helps to understand ways in which man interacts with hydrological systems, which behavior (s) can lead to transformations of hydrological functions, and how man reacts to these changes. While, community assets help to understand how the communities can sustainably manage themselves by identifying and mobilizing the existing, but often unrecognized assets, and thereby respond to and create local opportunities for themselves instead of depending on resources from outside. In most cases, the bio-cultural and Asset Based Community Development (ABCD) approaches have been used separately to study the involvement of people and their behavior towards water resource management. It is expected that integrating of these two approaches can be useful in understanding the links between hydrology and local systems; at the same time understanding how a community can restore and be resilient to the changes that occur to the aquatic ecosystems from a cultural, social, economic, political, and biological perspectives. The combination of bio-cultural and ABCD approaches can also, be a better strategy for identifying the parameters and functional relationships which can be used in sociohydrological model simulation.
\end{abstract}

Keywords: Biocultural, Community, Asset, Catchment and Resources

\section{Introduction}

Achieving water security is one of the key sustainability challenges faced by both developed and developing countries in this modern era $[1,2]$ It is projected that by 2025 , two third of the world's population would be living in severe water stress conditions [3]. The challenge becomes more complex due to dynamics and co-evolution of coupled manwater systems $[4,5]$. Man and his actions are considered as the main reasons for these dynamics [6]. Man interacts with water in multiple ways, ranging from biological/ecological, cultural, political and social to economic and public health dimensions [7]. Man needs water for various uses such as agricultural production, energy, potable water, religion, arts, 
recreation, and transport $[8,9]$. Thus, the role of water in social lives is significant [8] and nothing can replace water in human lives. However, rapid changes in the environment and social systems $[10,11]$ such as rapid population growth, rapid and extensive industrialization, pollution, climate uncertainty, enhanced life style, over-allocation and mismanagement of freshwater resources have facilitated overexploitation and destruction of hydrological systems, which can later cause negative feedbacks to the social system. The negative feedbacks may be in the form of saltwater intrusion [12], flood [13, 14], migration [15] drought, diseases [16, 17] water conflicts between riparian states, drought, and loss of economic opportunities [9]. Because of these stresses policy makers and experts have been emphasizing on the need for a holistic sustainable catchment management for sustainable water resources development. Scholars e.g. [6, 10, 5, 9] suggest that water crises can be solved by exploring, understanding, and interpreting the dynamics, interactions, and feedbacks between human actions and water cycle that co-evolved over time and space. This implies that, man must be considered as central to the hydrological system. It is also believed that community decision on participation in water resources management is influenced by history, education, institutions, socio-economic growth, and natural resources available [18, 19, 7, 9], as well as culture comprising norms, value, knowledge, needs, technology, and experiences.

Man lives in a world of diversity in terms of flora, fauna and human society. The variety of flora and fauna constitutes biodiversity, while the variety in human society with its multiplicities of culture is called cultural diversity [20] the interface of biodiversity and cultural diversity is referred to as bio-cultural diversity [21]. Of recent, an increase of pressure from human activities coupled with rapid extinction of human culture and languages have had negative impacts on natural resource management [22]. According to [18], man is dominant over nature and human societies depend on hydrological systems to sustain themselves and thrive. In turn, natural resources depend on human stewardship to sustain their vitality and resilience. This relationship sustains life [20]. The inextricable links between cultural and natural/biological assets are thus being increasingly viewed as key elements in achieving water sustainability as they can help to understand and interpret different scenarios of how human culture can modify water cycle in terms of flows and stocks $[15,2]$.

Apart from the natural and cultural assets that communities possess, every society has other types of assets that are called anthropogenic assets. Anthropogenic assets include community strengths and potentials such as human asset, institutions, groups and associations, and physical assets [23, 24]. These anthropogenic assets, also termed 'external drivers', facilitate the interactions and dynamics occurring between nature and socio-cultural systems in either positive or negative ways $[25,24]$. The assets are also termed as external drivers [25]. The Asset Based Community Development (ABCD) approach is often employed to facilitate a better understanding of the roles of anthropogenic assets in driving the interactions and resulting dynamics between nature and soio-cultural systems. ABCD is a strategy for sustainable community-driven development [26]. It helps to recognize and identify the resources, skills and experience which communities possess and how to apply those resources for their own development [23].

The ABCD enables a shift in the understanding of interactions within communities from a deficiency, needs, and problem-based orientation, to an asset-based approach built on a foundation that communities can drive their development process by identifying and mobilizing existing assets [27]. The bio-cultural approach on the other hand provides a clear understanding of how people in different cultures around the world interact with hydrological systems and responds to hydrological dynamics resulting from their actions $[28,15,29,12]$. Therefore, the combined bio-cultural and asset based approaches will help to understand links and dynamics existing between social and water systems for sustainable water resource and catchment management in a changing, uncertain and unpredictable environment $[18,7]$. This is within the context of the principles and practice of participatory approach to development, where active community participation and empowerment are the basis of sustainable and economic development [27].

\section{Review of Literature and Theory}

\subsection{Likelihood of Biocultural and Community Asset Based Approach in Catchment Resources Management}

Water resources continue to be scarce while hydrological systems are being destroyed at alarming rates [30]. It is believed that socio-hydrology can be useful for tackling these problems since it is an interdisciplinary science that explores the co-evolution and self-organization of local systems in the landscape, with respect to water availability, while treating people as endogenous part of the water cycle [6]. Man dominates nature and also possesses powerful ways and means of utilizing hydrological resources and responds to hydrological dynamics in different ways. The utilization of hydrological resources is influenced by people's culture. The latter comprises values, beliefs, traditions, experiences, attitudes, skills, norms, infrastructures, and technology $[9,8]$ socio-economic systems such as population growth and the type of economic activities [9] institutions [8,9] and social networks [8]. Combined together, these factors can be divided into two groups, namely, bio-cultural, and community/ anthropogenic assets.

In recent years, a number of scholars attempted to explain the connection between nature, water and social systems [31, $32,33,12]$. Literature on this area shows further that the interactions and associated dynamics between people and nature are influenced by people's values, attitudes, and understandings. However, most of the existing frameworks such as Social-Ecological Systems framework and Ecosystem Services concept did not consider how an 
individual and collective behavior interact with each other to influence the interactions and dynamics in human-nature systems. [34, 12] recommended more work is required to explore the role of behavior at both individual and collective levels in understanding the socio-nature system.

Previously, the bio-cultural and Asset Based Community Development (ABCD) approaches were used separately to study the involvement of people and their behavior toward water resource management. For example, ABCD was a strategy for sustainable community-driven development [26]. The appeal of ABCD lies in the premise that communities can sustainably manage themselves by identifying and mobilizing existing, but often unrecognized assets (including norms, values, understanding, institutions, skills and customs), and thereby respond to and create local opportunity for themselves instead of depending on resources from outsiders [34]. ABCD also provides an opportunity for the inclusion of local stakeholders in the management process while building strong, resilient and sustainable communities, and at the same time, ensuring that communities are fair, equitable and strong in the face of so much global change such as freshwater scarcity [26]. On the other hand, biocultural diversity helps to understand ways in which man interacts with hydrological systems, which behavior (s) can lead to transformations of hydrological functions, and how man reacts to these changes [15, 35, 7, 34]. Little is known about the integration of these two approaches in understanding the links between hydrology and local systems, particularly in Africa.

The integration of these two approaches is unique in two ways. First is the utilization of a non-traditional community development strategy that recognizes and mobilizes community assets at multiple levels. This is a departure from a deficiency, need-based model which reinforced the perceptions of rural people as predatory, poor and dependent [36]. Instead, it focuses on a process that stresses the importance of local assets and perspectives, while building relationships which are necessary for sustainable development and management [37]. The second way is through using a bio-cultural diversity lens, which utilizes a bio-cultural framework that allows researchers and practitioners to move away from the view that people are external drivers in hydrological systems, to the view that humans are central to the hydrological System [38].

It is believed that these approaches when combined can promote a holistic understanding of water resource management from a cultural, social, economic, political, and biological perspective to an understanding of the ways man interacts with and modifies hydrological systems, the impacts of their behavior, and how they respond to those changes. All these are achieved without undervaluing the influence of community assets, toward catchment management. The combination of bio-cultural and ABCD approaches can be a better strategy for identifying the parameters and functional relationships that can be used in socio-hydrological model simulation.

\subsection{Man-Nature Relationship in Catchment Environment}

Men are connected to catchment ecosystem, and catchment ecosystems are connected to men in complicated ways [5]. These connections evolve over time [6]. The complexity of these connections may vary across societies, climatic zones and regions, due to a number of factors such as catchment hydrology, population dynamics, socio-economic systems including culture, institutions, water related economic activities, ecosystem services and climate change $[39,18,15$, $12,7,40]$. It is universally known and accepted that the aquatic ecosystem is crucial for nourishing human's life and vice versa [8]. Despite the win-win situation existing between them, humans have been modifying the aquatic ecosystem in various ways, and the change in the aquatic system's ability to provide goods and services have in turn, influenced changes in human behavior and decision-making regarding the aquatic ecosystem [5]. Regardless of modification or changes that occur between aquatic ecosystem and humans, the competition between resources such as water for humans and water for the environment is ultimately mediated by humans alone, acting for both themselves and for the environment which cannot speak [41]. This scenario, in most cases, makes humans become greedy and think only for themselves and ignore nature. In the short term, humans can benefit much by ignoring nature but in the long run, they will start to experience unintended consequences such as salinization, flood, drought and diseases.

Human-nature relationship refers to the ways in which individuals or a group of individuals conceptually relate to nature [42]. In this context, the concept "nature" will be in terms of aquatic ecosystems, particularly catchments. The interactions between humans and nature can be well understood in the conceptualization of the socio-cultural aspect of human life in relation to nature, that is, the complex relationship between human and their natural environment [34]. The socio-cultural concepts include worldview, norms, beliefs, thoughts, actions, institutions, livelihood and practices, value, and attitude [24, 43, 44, 34].

According to $[42,44]$, the human - nature relationship has 3 dimensions, positionality (humans is above nature, human as part of nature, and humans and nature are equal), character of bond (addresses how humans are close to or away from nature) and understanding nature (how humans understand and manage changes occurring in the natural system). Moreover, the human - nature relationship can be captured using typology [44, 34, 42]. There are about 6 typologies of the relationship between man and nature. [45] describe four types, which are; master over nature, steward of nature, partner with nature and participant in nature. Of recent, [42] included more typologies, which are; user and apathy. However, there is also another type which is called 'nature distant guardian'. A better understanding of the typologies of nature-human relationships offer insights to the understanding of man's behaviors that influence their actions towards conservation practices $[42,12]$ observe that more 
work is required to understand the way humans value water, their behavior toward water usage, and how they respond to hydrological fluctuations at both individual and collective levels.

In this review, the key bridge linking human and nature is ecosystem good and services. These ecosystem services are categorized into 4; namely provision, regulation, supporting, and Cultural Ecosystem Services [33]. CES refers to nonmaterialistic services where people can benefit through spiritual enrichment, cognitive development, reflection, recreation, and aesthetic experiences. The CES seems to be a residual category of enjoyable aspects of nature [33]. This reviewed study is against the idea of CES being a residual part of the ecosystem. Instead, it emphasizes on CES as an important component that defines and determines the relationship existing between human and nature. The review recommends the use of nonmaterial services of ecosystem to find out why and how humans value nature for sustainable aquatic ecosystem exploitation.

\subsection{Framework of Interaction Between Human and Natural Systems}

Universally, there are so many frameworks that try to explain the relationship between man and nature. The frameworks which are used include the Ecosystem services Social-Ecological Systems the Intergovernmental sciencepolicy Platform on Biodiversity and Ecosystem Services and biocultural diversity $[46,47,48,24,22]$. Except the Intergovernmental science-policy Platform on Biodiversity and Ecosystem Services (IPBES) and biocultural diversity, the rest of the frameworks do not adequately measure and operationalize the dynamics of people's norms, value, understanding and attitude in relation to natural resources at both individual and collective levels. As observed, the dynamics occur as a result of the fact that man-nature interaction is facilitated by anthropogenic assets, institutions and governance such as community assets [24]. The Asset Based Community Development (ABCD) approach has been used by a number of scholars such as so as to understand how these community assets facilitate the dynamics between mannature interaction [49-53]. The current review believes that a combination of $\mathrm{ABCD}$ and biocultural approach will elucidate the dynamics that occur in the catchments as a result of human action, and understand how communities are resilient to these changes at individual and collective levels. This is because biocultural approach will help to explore the diversity of knowledge, practices, the way of living together, values and belief systems, language and artistic expressions and how communities use them to cope with the dynamics of the catchments of good and services [54]. Furthermore, the review believes that $\mathrm{ABCD}$ helps to elucidate the ways in which communities link with the catchment and build strong, resilient and sustainable communities in the face of so much global change.

\subsubsection{Bio-Cultural Approach}

The bio-cultural approach provides a way of expressing the concept of an "inextricable link" between cultural and biological diversity [55] and the way through which the implications of this links could be explored [22, 56]. The discussion about the link between nature and human culture started in the early 1990s [57]. However in 2000s, the concept became popular and many scholars have been advancing it rapidly [58]. The concept has now spread globally. Different international organs, policy instruments and international scientific assessments recognize the advantages of integrating culture and bio-physical aspects such as the $[59,33,60]$. The advantages include conservation and promotion of cultural diversity; conservation and sustainable use of biological diversity and other natural resources; and equity in access to and distribution of benefits from integrated and participatory approaches to sustainable management of the coupled social ecological systems [59, $33,60]$.

Over the last twenty seven years, there has been a growing body of literature supporting the link between biological and cultural diversity $[61,21,62,63,64,65]$. The earliest evidence of this link can be found in the global macrogeographic distribution of languages (used as a proxy for culture) and areas of high biodiversity [66, 67, 68]. While these studies and others have established regional, national and global scale correlations between biological and cultural diversity, researchers are now engaging in detailed case studies at the local level to understand the links between environment and cultural values, beliefs, institutions, knowledge systems, practices, and languages [21].

Culture is a complex and broad set of relationships, values, attitudes, norms and behaviors that bind a specific community consciously and unconsciously [69]. Cultural diversity refers to the variety of human cultures or societies in a given region and across the world. This includes the diversity of knowledge, practices, technology, and the way of living together, values and belief systems, language and artistic expression [18]. Biodiversity is the range of variety found among microorganisms, plants, fungi, and animals with their associated physical and chemical environments [54].There is a mutual relationship between cultural diversity and the regional environment and natural resources. The history of the environment shows that the depletion of ecosystem resources is the 'precursor' of the destruction of human civilization [58] that is, changes of human civilization is the outcome of the change of the environment [70]. The human society and their cultures shape the biodiversity and biodiversity shapes the human society and their cultural practice. The varieties in both culture and nature are connected, related and unified phenomena [22]. The unified phenomena between cultural diversity and nature are what are termed as biocultural diversity [20]. Biocultural diversity is defined as "the total variety exhibited by the world's natural and cultural systems. This explicitly considers the idea that culture and nature mutually constitute, and denote three concepts. Firstly, diversity of life includes human cultures and languages; secondly, there are links between biodiversity and cultural diversity; and finally, these links 
have developed over time through mutual adaptation and possibly co-evolution. Biocultural diversity incorporates ethno-biodiversity" [24]. Among all the components of cultural diversity, language seems to be the key means of transfer of knowledge. This characteristic makes language to be the main proxy of cultural diversity. Using language, communities can capture, maintain and convey information on local territories, species, ecosystems, and landscapes. Through the richness of linguistic diversity, knowledge and technology are developed and passed from generation to generation [20, 54].

Despite that a number of scholars have attempted to explore the links between natural and cultural resources, there is still scanty information on how these links can be used to understand the dynamics and resilience in aquatic ecosystem. The current review explores the links between aquatic natural and cultural resources using these links to understand and to find a way on how local community are or can built resilience toward changes that occur in the catchments.

\subsubsection{Asset-Based Approach to Community Development (ABCD)}

Asset based community development can be defined as, "...a strategy for sustainable community-driven development" [26, 37] defines $\mathrm{ABCD}$ as a methodology and strategy for the sustainable development of communities based on the strengths and potentials the community possess. This approach conforms with participatory approach principles, since it allows community to empower themselves through utilization of assets that they already possess instead of depending on the resources from outside. The approach helps to recognize and identify the resources, skills and experience communities have, and how to use these resources for their own development [37]. The approach moves interactions with communities from a deficiency, needs, and problembased orientation to an asset-based approach, built on a foundation that communities can drive the development process by identifying and mobilizing existing assets [27]. ABCD's approach is in line with the principles and practice of participatory approach to development, where active participation and empowerment are the basis of practice. It is a strategy which is directed towards sustainable economic development that is community-driven [71]. The approach reflects on the early conceptualizations of participatory action research [34]. [72, 37] coined the term in the early 1990s after observing that most development initiatives relied heavily on external people and agencies, while community assets were under-recognized and underutilized. [73, 37] also wrote the seminal work in the field, a book called Building Communities from the Inside Out. The book is written as a guide, defining $\mathrm{ABCD}$, outlining its foundational principles and summarizing lessons learned by studying successful community-building initiatives across the United States [26]. There are five groups of assets inventories in ABCD; these include individuals, institutions, physical, groups and association, and connections [71]. These community assets, if well utilized, can help to build strong, resilient and sustainable communities, while ensuring that communities are just, fair, equitable, and strong in the face of so much global change [74].

Because of the patentability of the ABCD approach, $A B C D$ principles are frequently integrated with a complementary concept or framework to create a unique approach. Two very recent examples are from [52, 53]. According to [52] work explores the potential relationship between $\mathrm{ABCD}$ and community-based tourism, with the goal of improving community-based tourism's inconsistent record in delivering community development. The authors suggest that $\mathrm{ABCD}$ can, and should, be applied to community-based tourism [52]. Similarly, [53] study offers an integrated framework and practice model of sustainable livelihoods and the ABCD approach. According to [53], the integrated sustainable livelihoods/ABCD framework is useful in understanding the strengths of a vulnerable community in order to plan and implement sustainable community development strategies. Community assets have proven to be effective in enhancing the adaptive capacity in different dynamics however, little is known on how such assets facilitate aquatic ecosystem dynamics. Apart from proposing the integration between $\mathrm{ABCD}$ approach and the biocultural diversity (BCD) approach, $\mathrm{ABCD}$ by itself, will be used to identify influential assets that facilitates the usage of biocultural resources found in the catchments. These influential assets can also help in understanding the links and dynamics occurring in catchment areas, and how communities are showing resilience in adopting or coping with those dynamics.

\section{Conclusion}

It has been proven that men have a big and central role in use and control aquatic ecosystem because they live and work on aquatic ecosystem for survival, and they tend to respond differently to the emerging environmental changes including water scarcity. However, the main challenge is how to restore, adapt and manage the degraded hydrological cycle to new conditions that can support high population densities and activities, without hindering development. This review support that multidimensional and participatory approaches in freshwater ecosystem management are important in addressing complex problems of hydrological systems. However, the review go further saying the participatory approaches can be effective in solving water problems if both biocultural and community based assets will be integrated into the process. This is because the relationship between human being and water and behavior toward utilization is influenced by the resources available which can be categorized into biocultural resources and community assets. 


\section{References}

[1] Conca, K. (2008). The United States and international water policy. The Journal of Environment \& Development, 17 (3), 215-237.

[2] Sivapalan, M., Konar, M., Srinivasan, V., Chhatre, A., Wutich, A., Scott, C. A., \& Rodríguez-Iturbe, I. (2014). Sociohydrology: Use-inspired water sustainability science for the Anthropocene. Earth's Future, 2 (4), 225-230.

[3] Food and Agriculture Organization (FAO) (2012), "Water scarcity" http:www.fao.org/nr/water/topics_scarcity. Html.

[4] Elshafei, Y., Coletti, J. Z., Sivapalan, M., \& Hipsey, M. R. (2015). A model of the socio-hydrologic dynamics in a semiarid catchment: Isolating feedbacks in the coupled human-hydrology system. Water Resources Research, 51 (8), 6442-6471.

[5] Troy, T. J., Pavao-Zuckerman, M. \& Evans, T. P. (2015). Debates-Perspectives on socio-hydrology: Socio-hydrologic modeling: Tradeoffs, hypothesis testing, and validation. Water Resources Research, 51 (6), 4806-4814.

[6] Sivapalan, M., Savenije, H. H., \& Blöschl, G. (2012). Sociohydrology: A new science of people and water. Hydrological Processes, 26 (8), 1270-1276.

[7] Walker, E., Loucks, D. P \& Carr, G. (2015). Social Responses to Water Management Decisions. Environ. Process. (2015) 2: 485-509.

[8] Krause, F. \& Strang, V. (2016). Thinking relationships through water. Society \& Natural Resources, 29 (6), 633-638.

[9] Pande, S. \& Sivapalan, M. (2017). Progress in sociohydrology: a meta-analysis of challenges and opportunities. Wiley Interdisciplinary Reviews: Water, 4 (4). Sivapalan, M., Konar, M., Srinivasan, V., Chhatre, A., Wutich, A., Scott, C. A., ... and Rodríguez-Iturbe, I. (2014). Socio-hydrology: Useinspired water sustainability science for the Anthropocene. Earth's Future, 2 (4), 225-230.

[10] Montanari, A., Young, G., Savenije, H. H. G., Hughes, D., Wagener, T., Ren, L. L., and Blöschl, G. (2013). "Panta Rhei-everything flows": change in hydrology and societythe IAHS scientific decade 2013-2022. Hydrological Sciences Journal, 58 (6), 1256-1275.

[11] Montanari, A. (2015). Debates-Perspectives on sociohydrology: Introduction. Water Resources Research, 51 (6), 4768-4769.

[12] Elshafei, Y., Sivapalan, M., Tonts, M., \& Hipsey, M. R. (2014). A prototype framework for models of sociohydrology: identification of key feedback loops and parameterisation approach. Hydrology and Earth System Sciences, 18 (6), 2141-2166.

[13] Di Baldassarre, G., M. Kooy, J. S. Kemerink, \& L. Brandimarte (2013a). Towards understanding the dynamic behaviour of floodplains as human-water systems, Hydrol. Earth Syst. Sci., 17, 3235-3244.

[14] Di Baldassarre, G., A. Viglione, G. Carr, L. Kuil, J. L. Salinas, and G. Bl€oschl (2013b), Socio-hydrology: Conceptualising human-flood interactions, Hydrol. Earth Syst. Sci., 17, 32953303.
[15] Johnston, B. R. (2013). Human needs and environmental rights to water: a biocultural systems approach to hydrodevelopment and management. Ecosphere, 4 (3), 1-15.

[16] Gurarie, D., \& Seto, E. Y. (2009). Connectivity sustains disease transmission in environments with low potential for endemicity: modelling schistosomiasis with hydrologic and social connectivities. Journal of the Royal Society Interface, 6 (35), 495-508.

[17] Klaver, I. J. (2011). Introduction: water and cultural diversity. In Water, Cultural Diversity, and Global Environmental Change (pp. 3-7). Springer Netherlands.

[18] Zlinszky, A., \& Timár, G. (2013). Historic maps as a data source for socio-hydrology: a case study of the Lake Balaton wetland system, Hungary. Hydrology and Earth System Sciences, 17 (11), 4589-4606.

[19] Maffi, L \& Dilts, O. (2012). Biocultural Diversity Toolkit: Biocultural Approaches to Conservation \& Development. Terralingua, 5.

[20] Maffi, L., \& Woodley, E. (2010). Biocultural Diversity Conservation: A Global Sourcebook (1 edition ed.). London; Washington, D. C: Routledge.

[21] Maffi, L. (2005). Linguistic, cultural, and biological diversity. Annu. Rev. Anthropol., 34, 599-617.

[22] Kretzmann, J. P., McKnight, J. and Sheehan, G. (1996). A guide to capacity inventories: Mobilizing the community skills of local residents: ACTA Publications Chicago, ILL.

[23] Díaz, S., Demissew, S., Carabias, J., Joly, C., Lonsdale, M., Ash, N.,... \& Bartuska, A. (2015). The IPBES Conceptual Framework-connecting nature and people. Current Opinion in Environmental Sustainability, 14, 1-16.

[24] Hanspach, J., Hartel, T., Milcu, A., Mikulcak, F., Dorresteijn, I., Kovács-Hostyánszki, A., \& Báldi, A. (2014). A holistic approach to studying social-ecological systems and its application to southern Transylvania. Ecology and Society.

[25] Northwestern. (2009). Asset-Based Community Development Institute. Retrieved from http://www.abcdinstitute.org/abcd09/.

[26] Mathie, A., \& Cunningham, G. (2003). From clients to citizens: Asset-based community development as a strategy for community-driven development. Development in Practice, 13 (5), 474-486.

[27] Mathie, A., Cameron, J., \& Gibson, K. (2017). Asset-based and citizen-led development: Using a diffracted power lens to analyze the possibilities and challenges. Progress in Development Studies, 17 (1), 54-66.

[28] Johnston, B. R., Hiwasaki, L., Klaver, I. J., Ramos-Castillo, A., \& Strang, V. (Eds.). (2011). Water, cultural diversity, and global environmental change: Emerging trends, sustainable futures? Springer Science \& Business Media.

[29] Hiwasaki, L. (2011). 'Water for Life'... Water for Whose Life? Water, Cultural Diversity and Sustainable Development in the United Nations. In Water, Cultural Diversity, and Global Environmental Change (pp. 509-531). Springer Netherlands.

[30] Pan, A., Bosch, D., \& Ma, H. (2017). Assessing water poverty in china using holistic and dynamic principal component analysis. Social Indicators Research, 130 (2), 537-561. 
[31] Falkenmark, M. (2003). Freshwater as shared between society and ecosystems: from divided approaches to integrated challenges. Philosophical Transactions of the Royal Society of London B: Biological Sciences, 358 (1440), 2037-2049.

[32] Falkenmark, M., \& Rockström, J. (2004). Balancing water for humans and nature: the new approach in ecohydrology. Earthscan.

[33] Millennium Ecosystem Assessment, (2005). Ecosystems and Human Well-being: Synthesis. Island Press, Washington, DC.

[34] Muhar, A., Raymond, C. M., van den Born, R. J., Bauer, N., Böck, K., Braito, M.,... \& Mitrofanenko, T. (2017). A model integrating social-cultural concepts of nature into frameworks of interaction between social and natural systems. Journal of Environmental Planning and Management, 1-22.

[35] Rockström, J., Falkenmark, M., Allan, T., Folke, C., Gordon, L., Jägerskog, A.,... \& Postel, S. (2014). The unfolding water drama in the Anthropocene: towards a resilience-based perspective on water for global sustainability. Ecohydrology, 7 (5), 1249-1261.

[36] Campo, H. D and Wali, A. (2008). Applying asset mapping to protected area planning and management in the Cordillera Azul National Park, Peru. Ethnobotany Research and Applications, 5, 25-36.

[37] Kretzmann, J., \& McKnight, J. (1993). Building communities from the inside out: a path toward finding and mobilizing a community's assets. Evanston, Ill.; Chicago, IL: The AssetBased Community Development Institute, Institute for Policy Research, Northwestern University; Distributed by ACTA Publications.

[38] Wilson, N. J., Walter, M. T., \& Waterhouse, J. (2015). Indigenous knowledge of hydrologic change in the Yukon River Basin: a case study of Ruby, Alaska. Arctic, 93-106.

[39] Gregory, K. J. (2006) The human role in changing river channels, Geomorphology, 79, 172-191.

[40] Van Meter, K. J., Basu, N. B., McLaughlin, D. L., \& Steiff, M. (2015). The socio-ecohydrology of rainwater harvesting in India: understanding water storage and release dynamics at tank and catchment scales. Hydrology and Earth System Sciences Discussions, 12 (11), 12121-12165.

[41] Van Emmerik, T. H. M., Li, Z., Sivapalan, M., Pande, S., Kandasamy, J., Savenije, H. H. G.,... \& Vigneswaran, S. (2014). Socio-hydrologic modeling to understand and mediate the competition for water between agriculture development and environmental health: Murrumbidgee River basin, Australia. Hydrology and Earth System Sciences, 18 (10), 4239.

[42] Yoshida, Y., Flint, C. G., \& Dolan, M. K. (2017). Farming between love and money: US Midwestern farmers' humannature relationships and impacts on watershed conservation. Journal of Environmental Planning and Management, 1-18.

[43] Qin, H., and G. C. Flint. (2017). "Changing Community Variations in Perceptions and Activeness in Response to the Spruce Bark Beetle Outbreak in Alaska.” Sustainability 9 (1): 67.

[44] Braito, M. T., Böck, K., Flint, C., Muhar, A., Muhar, S., \& Penker, M. (2017). Human-Nature Relationships and Linkages to Environmental Behaviour. Environmental Values, 26 (3), 365-389.
[45] De Groot, M., \& van den Born. R. J. G. (2007). "Humans, Nature and God: Exploring Images of Their Interrelationships in Victoria, Canada." Worldviews: Global Religions, Culture, and Ecology 11 (3), 324-351.

[46] Millennium Ecosystem Assessment (MEA)(2003) Ecosystems and Human Well-Being: A Framework for Assessment. Washington, DC: Island Press.

[47] Ostrom, E. 2007. "A Diagnostic Approach for Going Beyond Panaceas." Proceedings of the National Academy of Sciences of the United States of America 104 (39): 15181-15187.

[48] Ostrom, E. 2009. "A General Framework for Analyzing Sustainability of Social-Ecological Systems." Science (New York, N. Y.) 325 (5939): 419-422.

[49] Curtis, A. L., \& Lefroy, E. C. (2010). Beyond threat-and assetbased approaches to natural resource management in Australia. Australasian Journal of Environmental Management, 17 (3), 134-141.

[50] Mathie, A. and Peters, B. (2014). Joint (ad) ventures and (in) credible journeys evaluating innovation: asset-based community development in Ethiopia. Development in Practice, 24 (3), 405-419.

[51] Chirisa, I. (2009). Prospects for the asset based community development approach in Epworth and Ruwa, Zimbabwe: A housing and environmental perspective. African Journal of History and Culture (AJHC), 1 (6), 028-035.

[52] Dolezal, C., \& Burns, P. M. (2015). ABCD to CBT: assetbased community development's potential for communitybased tourism. Development in Practice, 25 (1), 133-142.

[53] Nel, H. (2015). An integration of the livelihoods and asset-based community development approaches: A South African case study. Development Southern Africa (ahead-of-print), 1-15.

[54] UNESCO and the CBD Secretariat (SCBD) (2013). Links between Biological and Cultural Diversity. 4pp.

[55] Posey, D. A. (1999). Cultural and spiritual values of biodiversity. A complementary contribution to the global biodiversity assessment. In Posey, D. A. (ed.), Cultural and Spiritual Values of Biodiversity, UNEP and Intermediate Technology Publications, London, U. K., pp. 1-19.

[56] Pilgrim, S. \& Pretty, J. (2010). Nature and culture: An introduction. Nature and culture. Rebuilding lost connections. London: Earthscan.

[57] Posey, D. A \&and Dutfield, G. (1996). Beyond intellectual property: toward traditional resource rights for indigenous peoples and local communities. IDRC.

[58] Hong, S. K. (2013). Biocultural diversity conservation for island and islanders: necessity, goal and activity. Journal of marine and island cultures, 2 (2), 102-106.

[59] Declaration of Belem (1988) http://ise.arts.ubc.ca/documents/DeclarationofBelem. doc.

[60] Convention on Biological Diversity (CBD). (2011). Strategic Plan for Biodiversity and the Aichi Targets. Retrieved from Montreal: https://www.cbd.int/doc/strategic-plan/20112020/Aichi-Targets-EN. pdf.

[61] Mulder, M. B. and Coppolillo, P. (2005). Conservation: Linking Ecology, Economics, and Culture: Princeton University Press. 
[62] Posey, D. A. (2011). Indigenous Knowledge and Ethics: A Darrell Posey Reader (K. Plenderleith Ed. Reprint edition ed.). London: Routledge.

[63] Pungetti, G., Oviedo, G. \& Hooke, D. (2012). Sacred Species and Sites: Advances in Biocultural Conservation (G. Pungetti, G. Oviedo, \& D. Hooke Eds. 1 edition ed.). Cambridge; New York: Cambridge University Press.

[64] Loh, J. \& Harmon, D. (2014). Biocultural diversity: threatened species, endangered languages. WWF Netherlands, Zeist, the Netherlands, 1 .

[65] Agnoletti, M. and Rotherham, I. D. (2015). Landscape and biocultural diversity. Biodiversity and Conservation, 24 (13), 3155-3165.

[66] Chapin, M. (1992). The co-existence of indigenous peoples and environments in Central America. Research and exploration, 8 (2): 232-234.

[67] Gorenflo, L. J., Romaine, S., Mittermeier, R. \& WalkerPainemilla, K. (2012). Co-occurrence of linguistic and biological diversity in biodiversity hotspots and high biodiversity wilderness areas. Proceedings of the National Academy of Sciences, 109 (21), 8032-8037. Retrieved from http://www.pnas.org/content/109/21/8032.short.

[68] Stepp, J. R., Cervone, S., Castaneda, H., Lasseter, A., Stocks, G., \& Gichon, Y. (2004). Development of a GIS for global biocultural diversity. Policy Matters, 13 (267-270). Retrieved from http://wiki.bioculturaldiversity.eu/wpcontent/uploads/2010/04/Stepp-et-al-2004-BCD-and-GIS.pdf.

[69] Williams, R. (1958). Moving from high culture to ordinary culture. Originally published In: McKenzie $N$ (ed.), Convictions.

[70] Hoff, M. D. (2002). Effects of global warming on human cultural diversity. Encyclopedia of life support systems. 8pp.

[71] Rowland, S (2008). What is Asset Based Community Development (ABCD). 3pp.

[72] Fals Borda, O., \& Rahman, M. A. (1991). Action and knowledge: breaking the monopoly with participatory actionresearch: Apex Press.

[73] Ware, A. (2013). An assessment of empowerment through highly participatory asset-based community development in Myanmar. Development bulletin: challenges for participatory development in contemporary development practice, 75, 110114.

[74] International association for community development (IACD) (2009). What Are Asset-Based Approaches to Community Development? 7pp. 